\title{
MS\&T15 Converges on Columbus
}

\section{new and noteworthy at TMS}

Turn to this regular JOM feature for information on new TMS initiatives, updates, and overviews of TMS events and activities, and news from the field that impacts TMS and its members. To submit news items for consideration, contact Lynne Robinson, JOM Contributing Editor, at Irobinson@tms.org.

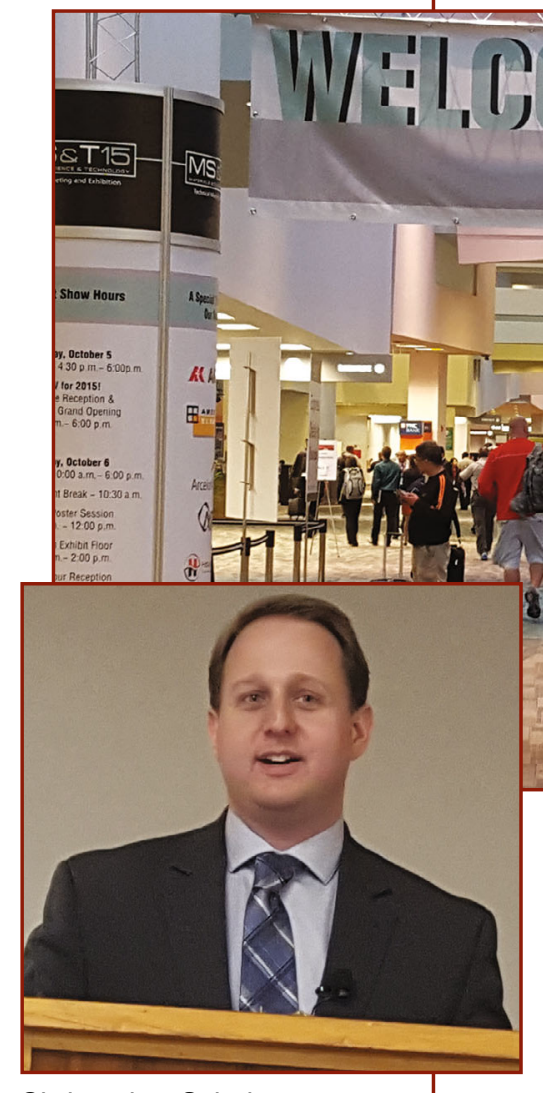

Christopher Schuh, 2015 TMS Fellow (above), encouraged young professionals to "avoid a tactical world view" when making career decisions when he spoke at the TMS Young Professional Tutorial Lecture. "Think long range and holistically about where you are going," Schuh said. "Develop an internal set of standards and live up to them. If you strive to be the person you want to be, then everything else will follow." Schuh is head of the Materials Science and Engineering Department at the Massachusetts Institute of Technology and the youngest person to ever be inducted as a TMS Fellow.
A highlight of the meeting's 13th installment was the all-conference plenary featuring award speakers from each of the organizing societies - the American Ceramic Society (ACerS), the Association for Iron and Steel Technology (AIST), ASM International, and TMS. (NACE International also participated as a programming partner.)

Sylvia M. Johnson, NASA Ames Research Center and the ACerS Edward Orton Jr. Memorial Lecture honoree, opened the session with an engaging overview of how materials scientists and engineers are addressing the unique challenges of sending (and returning) scientific expeditions to Mars. Harry Bhadeshia, University of Cambridge, and the AIST Adolf Martens Memorial

(enary

Steel Lecture honoree, followed with a detailed discussion on martensitic transformations.

Concluding the plenary was the TMS/ASM Joint Distinguished Lecture in Materials and Society, given by Vincent $\mathrm{J}$. Russo, Aeronautical Systems Center, Wright Patterson Air Force Base (retired). The premise of his topic, "What Is a Splendid Leader," was that scientists and engineers possess the analytical and problem-solving and a host of special events and networking opportunities drew more than more than 3,100 scientists and engineers to Materials Science \& Technology 2015 (MS\&T15) in Columbus, Ohio, October 4-8.

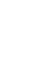




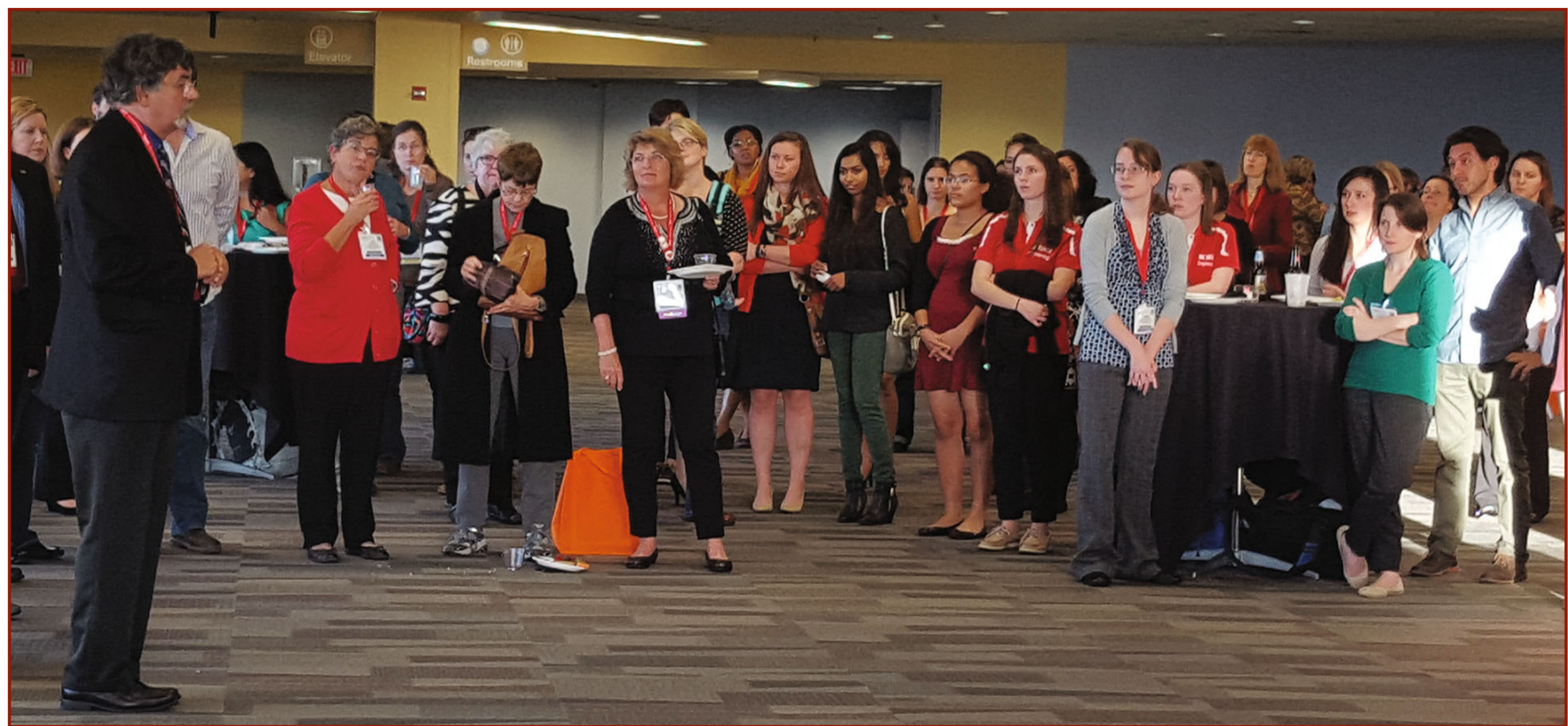

Patrice Turchi, 2015 TMS president (forefront, left), welcomes attendees to the very popular Women in Materials Science and Engineering Reception, along with the leaders of the other MS\&T15 organizing societies. skills. He then shared what he had identified as four pillars of leadership. (See sidebar for details.)

"I thought the plenary session was outstanding," said Patrice Turchi, 2015 TMS president. "It offered a great balance of perspectives. Sylvia Johnson's presentation provided a high- level discussion on how challenges are presented to and addressed by the scientific community, while Harry Bhadeshia offered a more specific technical talk. Vincent J. Russo then gave an excellent overview of the non-technical skills that scientists and engineers should cultivate, which I

\section{Superalloys Scholarship Awardees Recognized}

Congratulations to the two International Symposium on Superalloys Scholarship awardees, who were formally recognized for their achievements at MS\&T15. Lindsay Mullenix is a doctoral student at the University of Florida in the High Temperature Alloys Group. Paraskevas Kontis is a doctoral student at the University of Oxford with a research interest in the development of new polycrystalline superalloys for novel guide vanes in land-based turbines. The scholarships are funded annually by the Organizing Committee of the International Symposium on Superalloys.

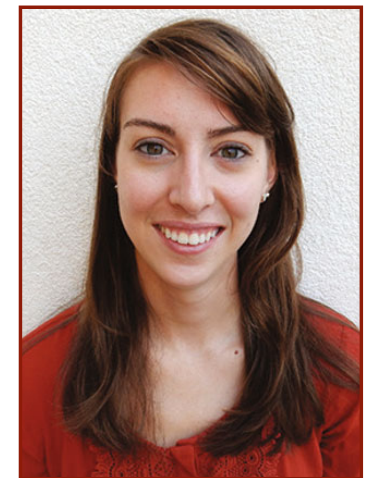

Lindsay Mullenix

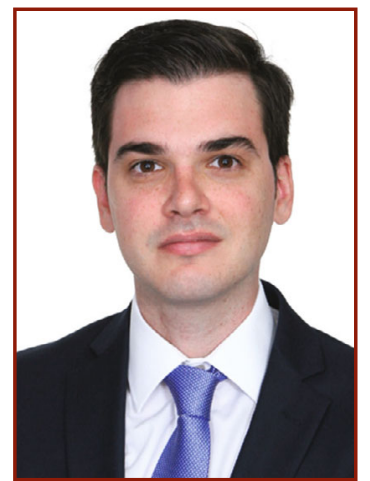

Paraskevas Kontis

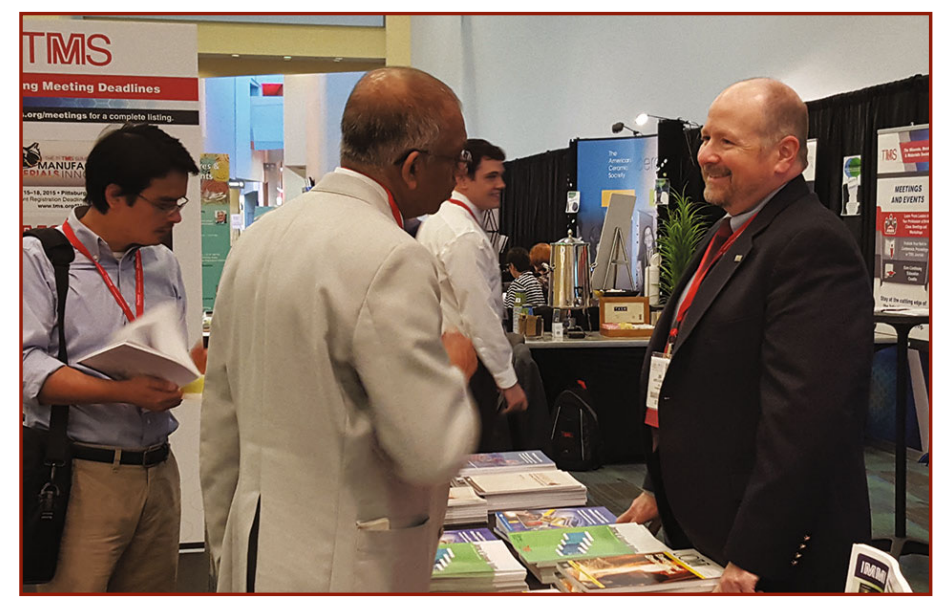

James J. Robinson, TMS executive director (right), discusses what's new and evolving at TMS at the TMS Members Lounge.

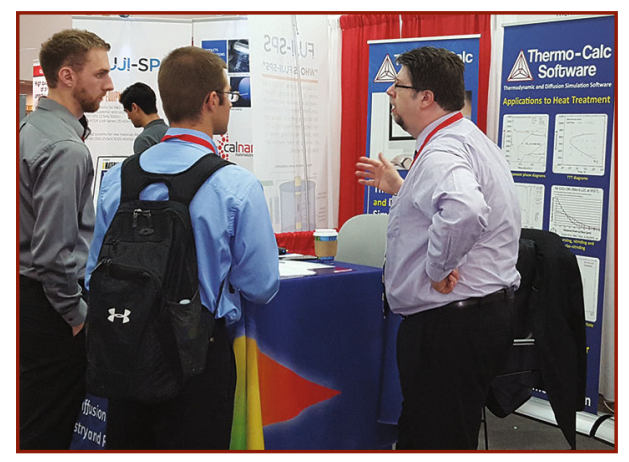

Subtle scheduling changes at MS\&T15 allowed even more opportunities for learning and networking at the MS\&T15 Exhibition. 
think was of great value to everyone who attended the session."

Turchi was also pleased with the overall high quality of MS\&T15 programming. "I think there has been constant progress on what we are offering at MS\&T, with well-attended sessions all the way through the end of the conference," he said. "The individual interests of the four organizing societies enable MS\&T to cover an extremely broad class of materials. However, I also believe that the volunteers responsible for the programming have collaborated very well to develop topics that cross-cut all the disciplines represented at the meeting."

MS\&T will travel next to a new location in 2016 - Salt Lake City, Utah, from October 24-27, 2016. Abstracts are being accepted until March 15, 2016 on such topics as additive manufacturing; biomaterials; electronic and magnetic materials; fundamentals, characterization, and computational modeling; nanomaterials; and processing and manufacturing. For additional details and to submit an abstract, visit the meeting website at matscitech.org.

\section{Distinguished Lecture Shares Framework for Leadership Development}

Nearly a third of Standard \& Poor's (S\&P) 500 companies are led by engineers as chief executive officers-a statistic that Vincent Russo uses to support his premise that engineers are uniquely equipped for leadership positions. "Engineers naturally possess the key attributes necessary for running a successful company," he stated in the opening minutes of the TMS/ ASM Joint Distinguished Lecture in Materials and Society at the MS\&T15 all-conference plenary. "They tend to be analytical problem solvers, system level thinkers, and have a practical, pragmatic orientation focused on building things that work."

At issue, noted Russo in his talk, is that engineers are rarely prepared to leverage these strengths into leadership skills. The optimum place to start this development, he said, is in undergraduate and graduate school, "but the technical denseness of academic programs do not currently allow for this."

The balance of Russo's presentation focused on sharing a leadership framework that he has developed based on his 41 years of experience in leading engineering organizations, most recently as executive

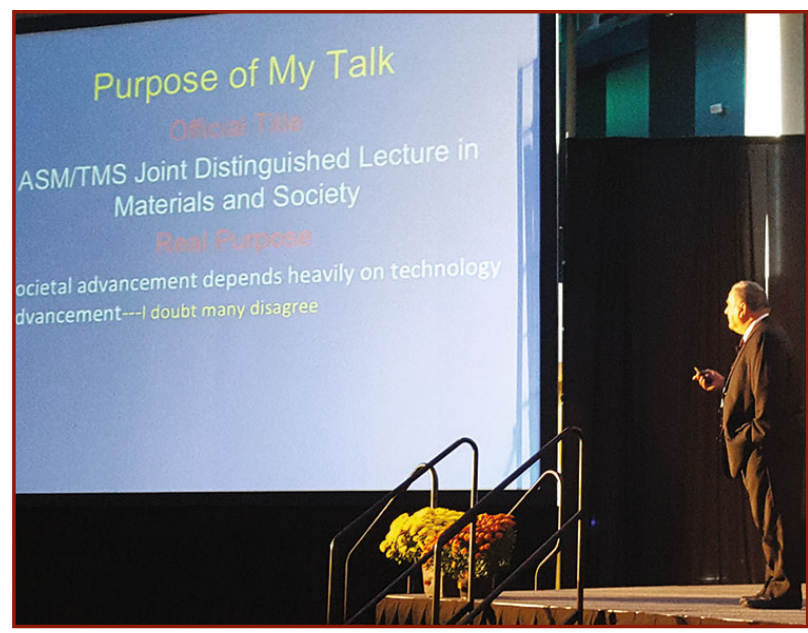

"What Is a Splendid Leader" was the topic of Vincent J. Russo's energetic TMS/ASM Joint Distinguished Lecture at the MS\&T15 all-conference plenary. director, Aeronautical Systems Center; Wright-Patterson Air Force Base (retired). The four pillars supporting this framework-Behavior Realities, Leadership Tenets,

Essence of Leaders, and Life Balance-work together to evolve an understanding of how to motivate and inspire others to "do something that needs to be done because they want to do it," said Russo, paraphrasing former U.S. President Dwight D. Eisenhower.

"Leaders are always role models, for the good, the bad, and the ugly," commented Russo in his concluding remarks. "You set the whole tone for the workforce and those you lead will reflect back everything you do. What you do is more important than what you say. Choose the shadow you cast carefully."

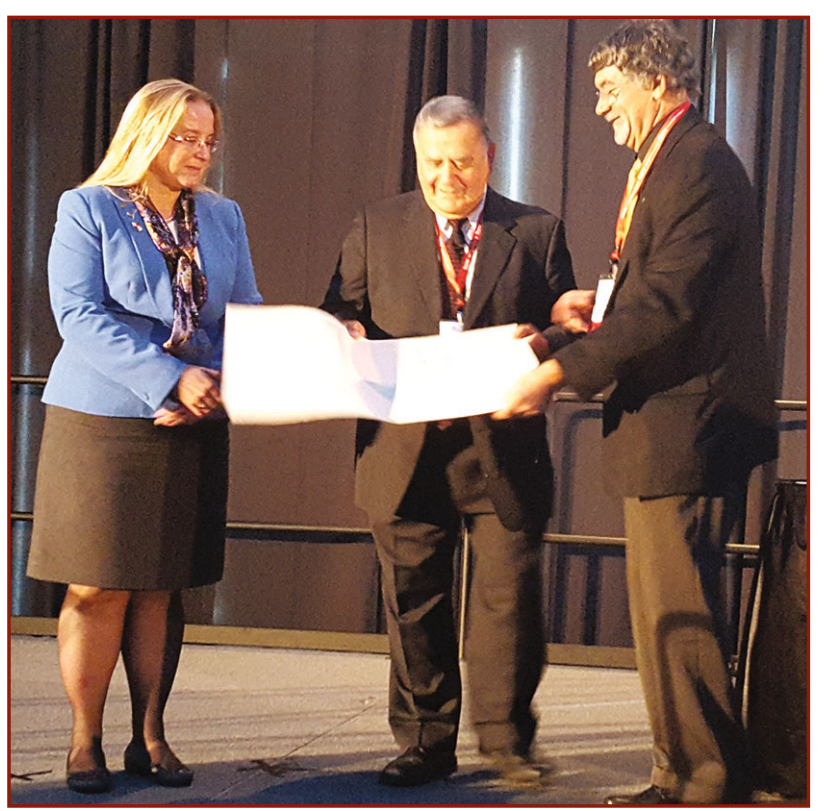

Sunniva R. Collins (left), Case Western Reserve University and 2014-2015 ASM International president, and Patrice Turchi (right), Lawrence Livermore National Laboratory and 2015 TMS president, present Vincent J. Russo (center), retired from the Aeronautical Systems Center at Wright-Patterson Air Force Base with the ASM/TMS Joint Distinguished Lecture in Materials Society. 


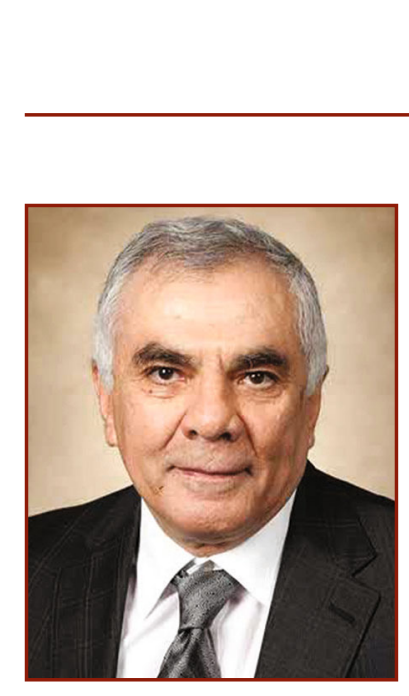

\section{TMS Awards Update}

\section{New TMS Award Honors Nagy El-Kaddah}

Applications are now being accepted for the new TMS Extraction \& Processing Division (EPD) Nagy El-Kaddah Award for Best Paper in Magnetohydrodynamics (MHD) in Material Processing. The award honors Nagy El-Kaddah for the lasting contributions he made in the field of transport phenomena and kinetics concerning the electromagnetic processing of materials. TMS member and one of El-Kaddah's former graduate students, Thinium Natarajan, associate research consultant at U.S. Steel, worked to establish this award in his late professor's memory.

"After obtaining my bachelor's degree in India, El-Kaddah offered me an opportunity to get involved in materials processing using electromagnetics. He and his family welcomed me and helped me adjust to being away from family and in a new country for the first time," Natarajan recalled. "On the professional side, he encouraged me to explore any area by taking classes. My daily discussions with him gave me an appreciation of his ability to see the big picture and then hone in on the problem to be solved."

This award is open to members and nonmembers involved in El-Kaddah's field of interest, materials processing. Scientific manuscripts published at conferences such as the TMS Annual Meeting \& Exhibition or journal manuscripts in the current year will be considered. The paper should be technical in nature, present new and significant information, and exemplify the application of science in solving a practical problem. The inaugural award recipient(s) will be recognized during the EPD/ Materials Processing \& Manufacturing Division (MPMD) Joint Luncheon Lecture at the TMS 2017 Annual Meeting \& Exhibition in San Diego, California.

El-Kaddah, a TMS member since 1979, influenced many lives and careers during his time as a professor at the University of Alabama's College of Engineering, beginning in 1985 . His work there led to three patents on container-less melting processes that allow metals to melt while suspended midair by electromagnetic fields. Prior to joining the university, El-Kaddah taught at Cairo University and worked as a visiting scientist and research associate at the Massachusetts Institute of Technology.

"According to El-Kaddah, no detail was too small to be overlooked while trying to successfully complete different projects," Natarajan noted of El-Kaddah's past work. "His desire for perfection and his push to get the job done right has been with his students over the past years."

Nominations must be submitted by April 1, 2016. Visit awards.tms.org for additional submission details and to access the nomination form. For questions on this award or guidance on submitting a nomination, e-mail Deborah Hixon, TMS Awards \& Recgonition Specialist, at hixon@tms.org.

\section{TMS Honorary Membership Recognizes Unconventional Contributors}

TMS is currently seeking candidates for its Honorary Membership Award. This recently introduced recognition opportunity aims to highlight individuals with varied backgrounds in leadership roles in industry, government, or academia who do not fit the typical TMS member profile. While these unconventional candidates may not have a technical background, they should exhibit excellence in both personal reputation and career achievements that have positively impacted the advancement of minerals, metals, materials, or related fields or industries.

Honorary members will receive full, professional membership in TMS for life, including all TMS member benefits. Nominations for current or recent members of the society will not be considered. Candidates must submit a nominator's cover letter of endorsement, a completed nomination form, and a current biography, resume, or curriculum vitae, by April 1, 2016 to awards@tms.org. Two-to-five 
letters of recommendation are optional, but not required. To access forms and for more information on how to submit a nomination, including a "Checklist for a
Good Nomination Packet," visit awards .tms.org and select "Honorary

Membership" from the drop-down menu at the bottom of the page.

\section{TMS Announces Updates to Fellow Award Bylaws}

The TMS Board of Directors approved updates to the bylaws for its most prestigious honor, TMS Fellow, at its October 2015 meeting. The focus of these recommendations was to ensure a balance among all sectors of the TMS membership - industry, academia, and government - through modifications in the selection criteria.

The changes refocus the selection criteria for each sector of TMS membership and the weight factor for each criterion now depends on the class of employment of the candidate. The classes of employment are presented as follows, with numbered categories, associated with subcategories that are not shown, listed in decreasing order of importance:

\section{A. Academia}

Broad and productive scholarship in science and engineering applications, teaching, or management as evidenced by:

1. Publication of articles and books of merit on work supervised or done by the nominee.

2. Direction of important research or engineering work.

3. Responsibility through management for widely known improvements and developments in minerals, metals, or materials science and technology; and Granting of patents to the nominee on scientific and technical developments in minerals, metals, or materials, in process methods, or in equipment for various fields of minerals, metals, or materials science and technology.

4. Outstanding service to TMS.

\section{B. Government}

Broad and productive scholarship in science and engineering applications, management and mentoring as evidenced by:

1. Publication of articles and books of merit on work supervised or done by the nominee.

2. Direction of important research or engineering work.

3. Granting of patents to the nominee on scientific and technical developments in minerals, metals, or materials, in process methods, or in equipment for various fields of minerals, metals, or materials science and technology; and Responsibility through management for widely known improvements and developments in minerals, metals, or materials science and technology.

4. Outstanding service to TMS.

\section{Industry}

Broad and productive scholarship in production, manufacturing, engineering applications, science, teaching, or management as evidenced by:

1. Direction of important research or engineering work.

2. Responsibility through management for widely known improvements and developments in minerals, metals, or materials science and technology.

3. Granting of patents to the nominee on scientific and technical developments in minerals, metals, or materials, in process methods, or in equipment for various fields of minerals, metals, or materials science and technology; and Publication of articles and books of merit on work supervised or done by the nominee.

4. Outstanding service to TMS.

For the full award bylaws, visit awards .tms.org and select "Fellow Award" from the drop-down menu at the bottom of the page. The Fellows Award is presented during the TMS-AIME Awards Ceremony held at the TMS annual meeting.

To nominate a colleague or friend for the 2017 Class of Fellows, a completed Fellow Nomination Form, nominator's cover letter of endorsement, five letters of recommendation, a short curriculum vitae (no more than five pages), and an extended curriculum vitae (for support) must be submitted to awards@tms.org by April 1, 2016. For questions on the changes to the Fellow Award, please contact Deborah Hixon, TMS Awards \& Recognition Specialist, at hixon@tms.org. 


\section{TMS Welcomes New Members}

\section{Please join us in congratulating the following new TMS members, approved by the TMS Board of Directors at its December 2015 meeting:}

Abbasi, Kevin; Case Western Reserve

University, United States

Adeosun, Samson Oluropo; University of Lagos, Nigeria

Assis, Paulo Santos; Ouro Preto Federal University, Brazil

Balogh, Michael P.; General Motors, R\&D, United States

Barwick, Brett; Trinity College, United States

Beaux, Miles; Los Alamos National Laboratory, United States

Blaiszik, Ben; University of Chicago, United States

Brissonneau, Laurent; CEA Cadarache, France

Bruni, Vittorio; United States

Cao, Liu; DNV GL, United States

Chan, K.C.; The Hong Kong Polytechnic University, Hong Kong

Chang, Shou-Yi; National Tsing Hua University, Taiwan

Chen, Xiang; ArcelorMittal Global R\&D, United States

Cheng, Xuan; Xiamen University, China

Cherepy, Nerine; Lawrence Livermore National Laboratory, United States

Chi, Feng; SELEE Corporation, United States

Choi, Hyun-Ju; South Korea

Chou, Yi-Chia; National Chiao Tung University, Taiwan

Chou, Kevin; University of Alabama, United States

Colijn, Hendrik; The Ohio State University, United States

Constant, Kristen Persels; lowa State University, United States

Cryderman, Robert; Colorado School of Mines, United States

Cui, Bai; University of Nebraska-Lincoln, United States

Culp, Jeff; National Energy Technology Laboratory-AECOM, United States

Dahal, Rajendra Prasad; Rensselaer Polytechnic Institute, United States
Decosta, John; TevTech LLC, United States

Degen, Cody; Center for Reliable Energy Systems, United States

Dekock, Joel Alan; Preco Incorporated, United States

Depottey, Austin M.; EJ, United States

Doleno, Linda; Sente Software, United States

Donohoue, Collin D.; Bechtel Marine Propulsion Corporation, United States

Dunstan, D.J.; Queen Mary University of London, United Kingdom

Evans, Wendy; Morgan Advanced Materials, United States

Fazeli, Fateh; CanmetMATERIALS, Canada

Filner, Joel; Varomet Corporation, United States

Flood, Joe; Bechtel Marine Propulsion Corporation, United States

Friedrich, Bernd; RWTH Aachen University, Germany

Fujieda, Tadashi; Hitachi Ltd., Japan

Gao, Pu-Xian; University of Connecticut, United States

Garza-Martinez, Luis; United States

Gbenebor, Oluwashina; University of Lagos, Nigeria

Ghose, Sanjit; Brookhaven National Laboratory, United States

Gloyn, Jason R.; Jacobs Technology, United States

Gomes, Joseph V.; Gomes Consulting LLC, United States

Grassman, Tyler J.; The Ohio State University, United States

Gupta, Subhadra; University of Alabama, United States

Halada, Gary Paul; Stony Brook University, United States

Han, Yuanfei; China

Hargather, Chelsey Z;; New Mexico Institute of Mining and Techology, United States

Harmon, Aaron; Accuride Corporation, United States

Heard, David; Alcoa Incorporated, United States

Horvath, Steven; University of California, San Diego, United States
Hou, Wenkao; ArcelorMittal, United States Hwang, Inho; United States Hwang, Joong-Ki; South Korea

Hyzak, Jack Michael; Precision Castparts Corporation, United States

James, Joshua; Mound Laser and Photonics Center Incorporated, United States

Jamshidinia, Mahdi; EWI, United States

Jin, Ran; Virginia Polytechnic Institute and State University, United States

Jitputti, Jaturong; SCG Chemicals Company Ltd., Thailand

Katti, Dinesh; North Dakota State University, United States

Kecskes, Laszlo J.; U.S. Army Research Laboratory, United States

Khan, Yusuf; University of Connecticut, United States

Koster, Gertjan; University of Twente, Netherlands

Koyama, Shinji; Japan

Krishnamurthy, Ramanathan; Purdue University, United States

Krizan, Daniel; Voestalpine Stahl GmbH, Austria

Lahiri, Indranil; Indian Institute of Technology, Roorkee, India

Lee, Seok-Jae; Chonbuk National University, South Korea

Lewinski, Nastassja; Virginia Commonwealth University, United States

Li, Dingqiang; Youngstown State University, United States

Liu, Ming; United States

Lu, Xiao-Gang; Shanghai University, China

Lu, Y. Charles; University of Kentucky, United States

Ma, Ji; Texas A\&M University, United States

Manami, Mori; Japan

Mangaldas, Tasha; University of Michigan, United States

Mares, Isaac; United States

Marks, Laurence D.; Northwestern University, United States 
Maurya, Deepam; Virginia Polytechnic Institute and State University, United States

McCloy, John; Washington State University, United States

Medina, Francisco; Arcam, Sweden

Mesplont, Christophe; Bekaert, Belgium

Mishra, Ajit; Haynes International, United States

Mitchell, Jeremy N.; Los Alamos National Laboratory, United States

Moffat, Martin W.; Cyril Bath Company, United States

Nam, Dae Geun; Korea Institute of Industrial Technology, South Korea

Natarajan, Thiyagarajan; John Crane Incorporate, United States

Neal, Michael; Inflection Consulting, United States

$\mathrm{Ni}$, Wangyang; Stryker, United States

Ota, Shusaku; JFE Steel Corporation, Japan

Passeri, Robert; Hitachi High-Technologies America, United States

Pitera, Jed; IBM Research, United States

Polasik, Alison; The Ohio State University; United States

Qian, Caifu; Beijing University of Chemical Technology, China

Rabe, Karin M.; Rutgers University, United States

Radman, Ljijlana; Hatch Ltd., Canada

Ramirez, Antonio J.; The Ohio State University, United States

Rasshchupkyna, Mariya; University of Hamburg, Germany

Rechard, Rob; Sandia National Laboratories, United States

Rhee, Chang Kyu; Korea Atomic Energy Research Institute, South Korea

Rickman, Jeffrey M.; Lehigh University, United States

Rimkus, Nathan W.; Los Alamos National Laboratory, United States

Roehling, John; Lawrence Livermore National Laboratory, United States

Rojas, Jessika V.; Virginia Commonwealth University, United States

Sabolsky, Ed; West Virginia University, United States

Salle, Christian; CILAS LAS, France
Schiesser, Hans; SHENMAO America

Incorporated, United States

Schwartzberg, John N.; Rocky Mountain EMTEC Incorporated, United States

Seaman, John; EWl; United States

Serkies, Kyle B.; Advantage Forensics, Canada

Servin, Rumualdo; Universidad Autonoma De Coahuila, Mexico

Shaner, Craig W.; Hanon Systems, United States

Sharma, Sanjeev; Nucor Steel Decatur, United States

Shen, Peng; Stackpole International, Canada

Shirpour, Mona; University of Kentucky, United States

Smith, Alice I.; Los Alamos National Laboratory, United States

Smith, Peter; Westminster College, United States

Swaminathan, Srinivasan; India

Sylven, Peter; Envicom AB, Sweden

Tang, Zhihong; Praxair Surface Technologies Incorporated, United States

Tang, Ming; Los Alamos National Laboratory, United States

Tao, Jing; Brookhaven National Laboratory, United States

Tashkandi, Mohamed; Northern Border University, Saudi Arabia

Task, Michael N.; Pratt \& Whitney, United States

Taylor, Jennings; Faraday Technology Incorporated, United States

Taylor, Christopher John; DNV GL, United States

Thimmegowda, Shalini; GE India Technology Center, India

Thomas, Roger Owen; TIMET, United Kingdom

Tobash, Paul; Los Alamos National Laboratory, United States

Tokarski, Tomasz; AGH University of Science \& Technology, Poland

Tran, Huan; University of Connecticut, United States

Valavala, Pavan; Dow Chemical Company, United States

Van Duren, Jeroen K.; Intermolecular, United States
Vanasupa, Linda Sue; California Polytechnic State University, United States

Walsh, Daniel W.; California Polytechnic State University, United States

Wang, Yong-Yi; CRES, United States

Wang, Zhi; China

Ward, Jeremy W.; United States

Wattoom, Jirut; SCG Chemicals Company Ltd., Thailand

Wedrychowicz, Mateusz; AGH University of Science \& Technology, Poland

Workman, David; EWI, United States

Worswick, Michael J.; University of Waterloo, Canada

Wu, Zhiwei; General Electric, China

Xu, Baoxing; University of Virginia, United States

Yadroitsev, Igor; Central University of Technology, South Africa

Yakubovsky, Oleg; ArcelorMittal USA, United States

Yang, Jian; The Dow Chemical Company, United States

Yatsuzuka, Taichi; Sumitomo Plastics America Incorporated, United States

Yeh, An-Chou; National Tsing Hua University, Taiwan

Yoshikazu, Nakai; Kobe University, Japan

Yu, Hang; Virginia Polytechnic Institute and State University, United States

Yu, Jianguo; Idaho National Laboratory, United States

Zeh, John Louis; Logan Aluminum Incorporate, United States

Zeng, Qiaoshi; National Tsing Hua University, United States

Zhang, Datong; South China University of Technology, China

Zhang, Mei; China

Zhang, Ying; Xiamen University, China

Zhang, Weiwen; China

Zheng, Baolong; University of California, Davis, United States

Zupan, Marc; University of Maryland; United States 